\title{
Editorial
}

\section{Sustainable Building Materials and Technologies}

\author{
Nadezda Stevulova, ${ }^{1}$ Kestutys Baltakys, ${ }^{2}$ Adriana Estokova, ${ }^{1}$ and Tomas Sverak ${ }^{3}$ \\ ${ }^{1}$ Department of Material Engineering, Institute of Environmental Engineering, Faculty of Civil Engineering, \\ Technical University of Košice, Košice, Slovakia \\ ${ }^{2}$ Department of Silicate Technology, Faculty of Chemical Technology, Kaunas University of Technology, Kaunas, Lithuania \\ ${ }^{3}$ Institute of Materials Chemistry, Faculty of Chemistry, Brno University of Technology, Brno, Czech Republic
}

Correspondence should be addressed to Nadezda Stevulova; nadezda.stevulova@tuke.sk

Received 8 December 2016; Accepted 8 December 2016; Published 16 April 2017

Copyright (C) 2017 Nadezda Stevulova et al. This is an open access article distributed under the Creative Commons Attribution License, which permits unrestricted use, distribution, and reproduction in any medium, provided the original work is properly cited.

The current production of building materials and construction technologies consuming the huge amounts of energy and natural raw material resources have also significant impact on the environment because of generation of greenhouse gases. Actual strategic role in sustainable construction consists of the rational use of material and energy resources by controlled minimization of the total production of emissions, with the emphasis on selection and use of such materials, design, and technologies, which accept requirements for quality, reliability, and functionality meeting the criteria of environment not only for optimal indoor climate but also more generally in prevention of the environmental pollution. New advanced materials and construction systems development are the challenge to make a major contribution to the transition to more sustainable and post-fossil-carbon future for our planet in changing climate conditions.

In this special issue, the papers are addressed to advances and application in cement and concrete material. The utilised industrial by-products as well as nonconventional environmentally friendly synthetic additives incorporating into cement/concrete for hydration process and strength development improvement are analysed in detail in some papers bringing innovative integrated solutions to key building materials.

M. Fridrichová et al. concentrate on thermodynamic stability of ettringite prepared by the hydration of yeelimite with emphasis on a new application of the fluidized bed combustion fly ash into Portland composite cements.

R. Ahmadi et al. pay attention to the research of a simple methodology of producing micro fine sized palm oil fuel ash by means of a laboratory scale wind tunnel system, as a new supplementary cementitious material that has a high potential for concrete and construction industry.

J. Doneliene at al. study the effect of synthetic hydrated calcium aluminate additive with different crystallinity on the hydration properties of ordinary Portland cement.

J. Wu et al. prepare a novel binary modified maltodextrin as a water-reducing agent for concrete.

Paper of X. Lv et al. investigate the performance and mechanism of cement pastes added with aluminium sulphate-based low alkali setting accelerator.

C. Wang and W. Li determine the factors affecting the mechanical properties of a new building material based on cement-mixed gravel.

C. Jiang et al. study the performance and microstructure of formed cementitious materials based on dune sand from waterway regulation engineering to produce concrete available in hydraulic engineering.

Paper of C. Xue et al. is aimed at an effective reusing of the construction waste composite powdered materials consisting of waste brick, fly ash, and mineral in small-scale prefabricated concrete. Their influence on working performance, mechanical properties, antipermeability, and antifrost performances was monitored.

Work related to the comparison of conventional and advanced concrete technologies applied in monolithic structures and precast units in terms of construction efficiency is presented by M. Špak et al.

Z. Li et al. study the effect of different diameter through the axial compression short concrete columns in steel tubes 
on their bearing capacity. A size-dependent model for predicting the axial bearing capacity of large, concrete-filled steel tubes is developed.

W. Gul et al. investigate an impact of hot pressing temperature on medium density fibreboard performance with emphasis on the strength and water resistance of the product.

Another important issue in suitable civil engineering is life cycle assessment. S.-M. Choi and Y.-S. Lee describe life cycle method with special attention directed to risk-weighted life cycle cost analysis for determination of the economic analysis for setting appropriate repair cycles on the material of fixed materials and facilities in the public rental housing.

Nadezda Stevulova Kestutys Baltakys Adriana Estokova Tomas Sverak 

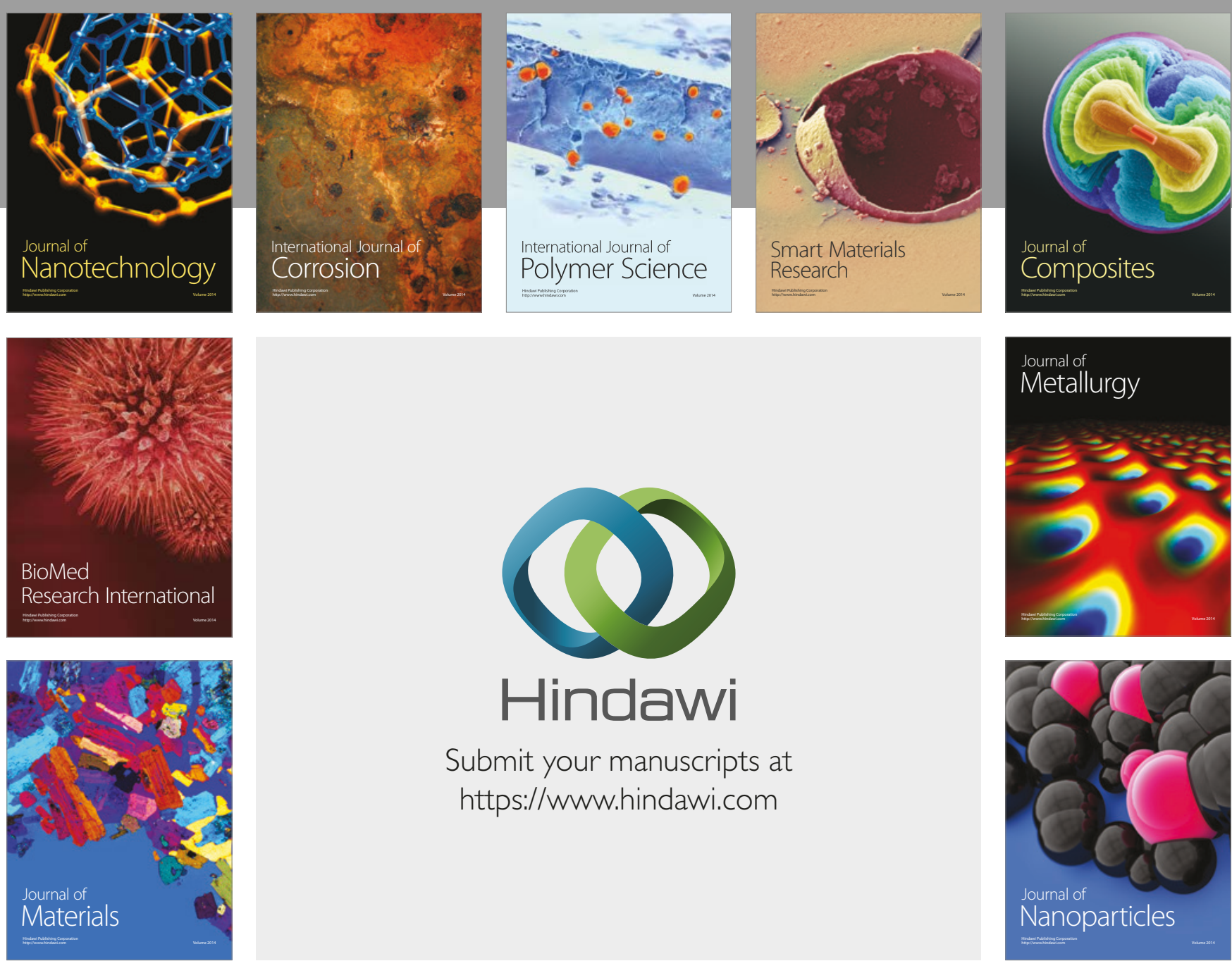

\section{Hindawi}

Submit your manuscripts at

https://www.hindawi.com
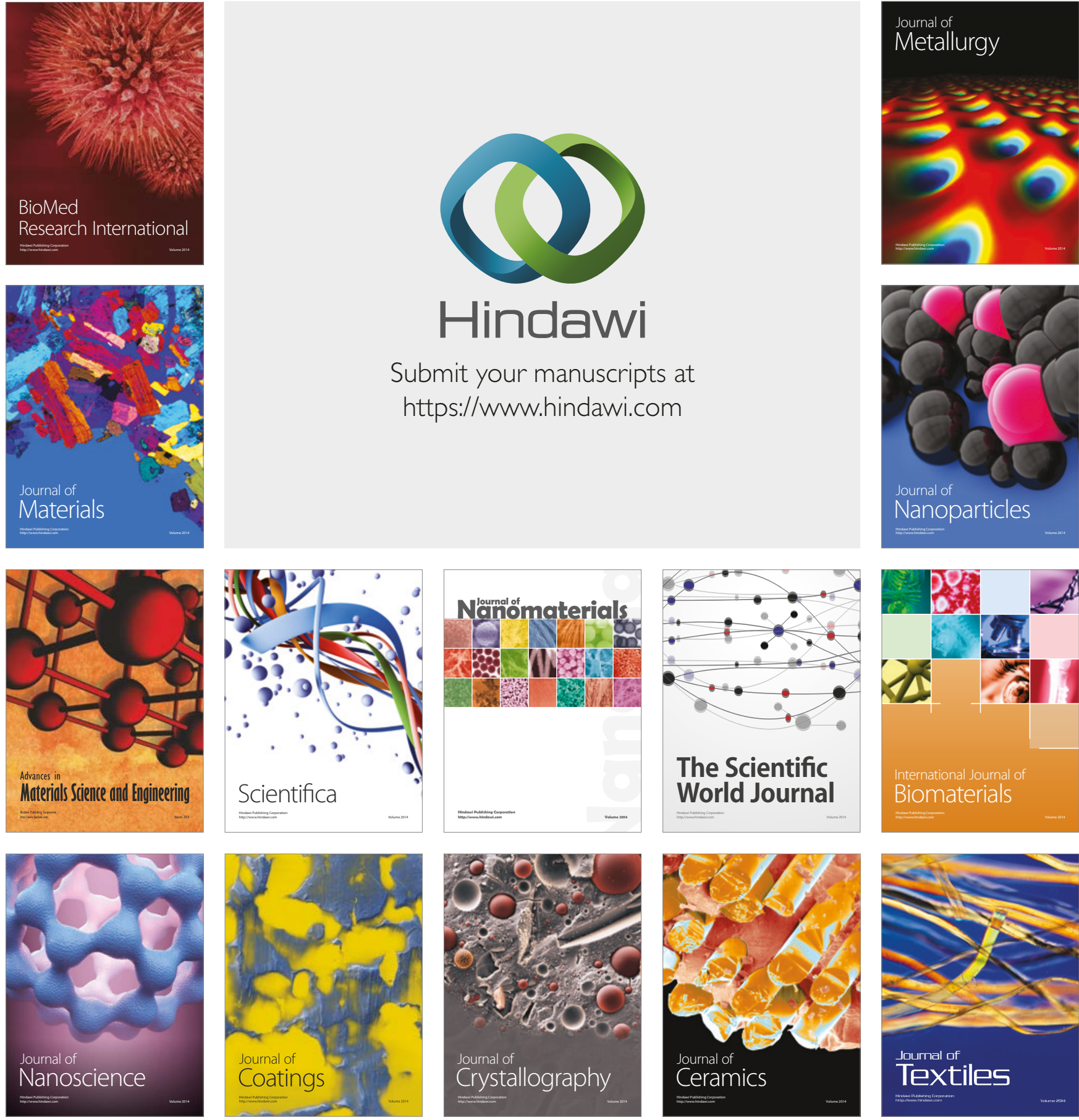

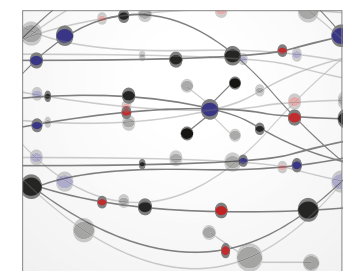

The Scientific World Journal
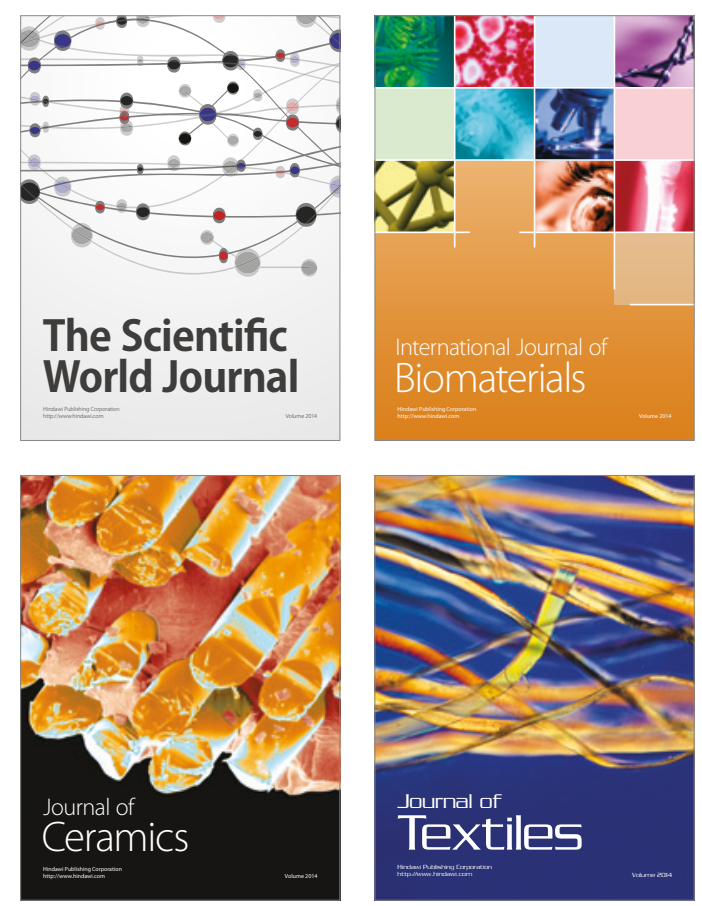